\title{
EFFECT OF INSTRUCTIONAL GUIDELINES ON NEWLY MOTHERS PRACTICES REGARDING CHILDREN TEETH PROBLEMS
}

\author{
Azza El-Sayed Ali Hegazy ${ }^{1}$, Ola Hussein AboElmaaty Mohamed ${ }^{2}$, \\ Manal Mohamed Ahmed Ayed ${ }^{3}$, Eman Mohamed Mohamed Elsherbeny ${ }^{4}$, \\ Safaa Ibrahim Ahmed ${ }^{5}$, Jihan Mahmoud Farrag ${ }^{6}$ \\ Pediatric Nursing Department, Faculty of Nursing El-Fayoum University ${ }^{1}$ \\ Community Health Nursing Department, Faculty of Nursing, El-Fayoum University ${ }^{2}$ \\ Pediatric Nursing Department, Faculty of Nursing, Sohag University ${ }^{3}$ \\ Community Health Nursing Department, Faculty of Nursing Bani-Suef University ${ }^{4}$ \\ Obstetrics and Gynecology Nursing Department, Faculty of Nursing, Sohag University ${ }^{5}$, \\ Pediatric Nursing Department, Faculty of Nursing, PortSaid University ${ }^{6}$
}

\begin{abstract}
Background: Understand the mothers about knowledge and the practices regarding their children teeth problems can support them and help them in caring among their children. Aim: To evaluate the effect of instructional guidelines on new mothers' practices regarding children's teeth problems. Subjects and method: Design: A quasi-experimental research design was used with a pre-and post-test. Setting: The research was conducted at the antenatal outpatient clinic at Sohag University Hospital, two Maternal and Child Health Centers that are attached to Sohag city and PortSaid city, which are Dar El -Salam Abed- Allah health center at Sohag city and El-Kuwait health center at PortSaid city. Subjects: A purposive sample of 260 primipara mothers was included. Two tools were used: (I) newly mothers' interviewing questionnaire (pre/post), which included (a) demographic characteristics; and (b) newly mothers' knowledge; and (II) observational checklist for oral hygiene practice (pre/post). Results: Revealed that mothers' ages ranged from 18 to 35 years, and the mean age was $23.2 \pm 4.5$ years. There were marked improvements in mothers' knowledge and practices regarding children's teeth problems after instructional guidelines implementation $(\mathrm{P}=0.005)$. Conclusion: The instructional guidelines implementation regarding teeth problems had a positive effect on improving new mothers of preschool children's knowledge and practices. Recommendations: The instructional guidelines for new mothers should be conducted regularly to discuss and teach them different aspects about teeth problems among their children and replication of the current study with a larger sample with follow-up.
\end{abstract}

Keywords: Instructional guidelines, Newly mothers of preschool children, Teeth problems 


\section{INTRODUCTION}

Dental problems are common during childhood disease; especially with acquire Streptococcus infection, which can interfere with good oral hygiene and a non-cariogenic diet (Petersen, 2014). Good education program and motivation of the mothers about oral health that needs practical, simple, effective, and low-cost ways to be carried out reflected on delivered care to the child. Pediatric dentistry nowadays is focused on promoting child oral health, healthy, good eating and hygiene habits are necessary to prevent oral diseases (Lemos, Zuanon, Myaki, \& Walter, 2018).

Dental problem is considered a worldwide and is a common problem in many countries (Gimenez, Bispo, Souza, Vigano, Wanderley, \& Mendes, 2016). The prevalence of dental problems among preschool-aged children is ranged from $6.2 \%$ to $41.6 \%$ and prevalence rates in the Middle East ranged from $11.1 \%$ to $33 \%$ have been reported (Bhayya \& Shyagali, 2013).

With a healthy mouth, the child can eat, speak, and communicate without experiencing any disease (Haque, Rahman, Itsuko, Mutahara, Tsutsumi, Islam, Mostofa, \& Kayako, 2016). But, poor oral health and infections can lead to negative effects on children as trouble in eating and sleeping and causes speech problems and low self-confidence. Children with a toothache had a low score on tests and their learning and school attendance records did not improve (Grossman, Cohen, \& Isman, 2010). Oral hygiene is important for the prevention of dental problems like dental cavities, gingivitis, and bad breath (Arora \& Sharma, 2012).

It is important to clarified knowledge and practices about teeth problems for mothers because mothers' knowledge and practices regarding these problems affected their children's dental caries. Children suffering from teeth problems are significantly associated with their mothers' poor knowledge and practices. Understanding such as these associations causes a broader view of the aspects that affected children's teeth problem, early detection, and treatment (World Health Organization, 2018).

Knowledge of mothers about the basic information regarding oral health will cause positive and healthy dental hygiene attitudes and practices that prevent teeth problems (Suma Hugar, Nalawade, Sinha, Hugar, \& Mallikarjuna, 2016). 
The nurses have an important role to help the parents in regulating the dietary intake for children and their habits regarding oral hygiene. Also, provide parents with ideas on the educational guidelines that are needed to promote oral health behaviors. Encourage mothers to mouth checks and referrals for any identified oral health concerns to ensure early identification of and intervention in teeth problems among children and provide intervention resources about oral health to parents. Equip parents with up-to-date information about the importance and benefits of fluoride as well as several other oral health promotion issues (Clausson, 2008).

Significance of the study:

Tooth decay prevalence in a study done by Shenoy \& Sequeira, (2013) among the group of 999 Egyptians, 496 boys, and 503 girls had teeth caries. Parents play an important role in teaching their children healthy oral hygiene habits (Saldunaite, Bendoraitiene, \& Slabšinskiene, 2014). Minimal attention to the primary prevention of teeth problems is being paid among mothers of preschool children that are necessary to have adequate knowledge and practice regarding healthy teeth. There is a lack of national studies that have examined the effect of instructional guidelines on mothers' knowledge and practices toward children's teeth problems. So, the researches aimed to evaluate the effect of instructional guidelines on new mothers' practices regarding children's teeth problems.

\section{AIM OF THE STUDY}

To evaluate the effect of instructional guidelines on newly mothers' practices regarding children's teeth problems

Study aim will be achieved through:

1. Assessing mothers' knowledge and practices regarding children's teeth problems.

2. Designing and implementing guidelines for improving mothers' knowledge and practices regarding children's teeth problems.

3. Evaluating mothers' knowledge and practices regarding children's teeth problems after implementing instructional guidelines. 


\section{Research hypothesis:}

Newly mothers' knowledge and practices regarding children's teeth problems will be improved after implementing the instructional guideline.

\section{SUBJECTS AND METHOD}

\section{Research design:}

A quasi-experimental research design (pre and post-test) was utilized in this study.

\section{Setting:}

The study was conducted at the Antenatal Outpatient Clinic affiliated with Sohag University Hospital, Egypt, this setting was selected due to the high prevalence of mothers in the selected setting, and also it serves the biggest region of the population from both rural and urban areas. And two Maternal and Child Health Centers that are affiliated to Sohag city and PortSaid city, which are Dar El-Salam Abed- Allah health center at Sohag city and El-Kuwait health center at PortSaid city and were selected because they are the nearest centers from the workplace.

\section{Subjects:}

A purposive sample included 260 primipara mothers from a population who have met the inclusion criteria in six months and received care from the antenatal clinic at Sohag University Hospital and the two previously mentioned centers from July 2020 until December 2020. The inclusion criteria were postnatal primipara mothers who had children from 3-6 years and who visited the antenatal clinic at Sohag University and selected $\mathrm{MCH}$ centers for receiving care and their child immunization, free from physical and chronic disease, and agree to share in this study. Mothers who suffered from chronic diseases were excluded.

\section{Tools of data collection:}

Two tools were used to collect the data of the study as the following:

Tool (I): Newly mothers' interviewing questionnaire: it was developed by the researchers (pre/post format) (World Health Organization, 2018; Lemos, Zuanon, 
Myaki, \& Walter, 2018; Gimenez, Bispo, Souza, Vigano, Wanderley, \& Mendes, 2016). It was written and adapted into the Arabic language to evaluate the effect of instructional guidelines on new mothers' practices regarding children's teeth problems. It included two parts:

Part 1: It included demographic characteristics of mothers such as age, level of education, working state, and residence.

Part 2: It included new mothers' knowledge about teeth problems such as Teeth, dietary habits, common teeth problems among preschool children, sources of information regarding their knowledge, and oral hygiene care. This part has 12 questions.

\section{Scoring system:}

If the mothers' answer was 'yes' the score was given 1 and if the answer was 'no' the score was given 0 . Mothers who scored between 1 and 4 were considered to have poor knowledge $(<50 \%)$, those who scored between 5 and $8(50 \%-<75 \%)$ were considered as having average knowledge, and those who scored between 9 and 12 were considered to have good knowledge ( $\geq 75 \%)$.

Tool (II): Oral hygiene observational checklist: It included six steps were developed by the researchers and guided by The Egyptian Society for Pediatric Dentistry (2015). The checklist of new mothers who performed it completely was considered 'done'; the score was given 1 and the checklist of those who left any step was considered 'not done; the score was given 0 . The total score was 6 marks.

\section{Validity of the tools:}

The content validity of the tools and the instructional guideline, its clarity, comprehensiveness, appropriateness, and relevance were reviewed by five experts in pediatric nursing, obstetrics and gynecological, community health nursing field, and oral and dental medicine to test the content validity before using it in the study. Modifications were made according to the panel judgment to ensure sentence clarity and content appropriateness. 


\section{Reliability of the tools:}

The Cronbach's $\alpha$ test was used to assess the reliability of the questions relating to knowledge, which was 0.86 and the reliability of the questions relating to reported practice was 0.89 .

\section{A pilot study:}

A pilot study was conducted on $10 \%$ (26) of the primipara mothers. The clarity and testing of the feasibility of the research process needed for modifications were carried out to develop the final form of the tools. Primipara mothers who were in the pilot were included in the study.

\section{Fieldwork:}

The study included 260 primipara mothers. The researchers attended previously selected settings two days / a week from 9 am to $12 \mathrm{pm}$. Data collection within 6 months from July 2020 until the end of December 2020. Data was collected from the studied mothers through interviewing questionnaires and an observation checklist. Approximately, 30-40 minutes were taken to complete each interview questionnaire.

After selecting the studied mothers, who met the inclusion criteria, the purpose and importance of the study were explained. Oral consent was obtained from studied mothers before participation in the study. The researcher collected data by distributing questionnaires to studied mothers; each question was explained to the studied mothers then answered by them.

The interviewing questionnaire and oral hygiene observational checklist were distributed to the studied twice; (1) pre-test to assess mother's knowledge and practices before implementing instructional guidelines. (2) Post-test to assess mother's knowledge and practices after implementing instructional guidelines.

The booklet was used as a supportive material and given to mothers in the Arabic language to cover all the knowledge and practical part of oral health after reviewing the related literature based on the assessment of the actual needs of the studied mothers. Different teaching methods were used such as lectures, discussion, 
demonstration, and re-demonstration, pictures, posters, teeth models, and real equipment were used.

The researchers designed and implemented the educational guidelines about teeth problems in the form of a theoretical part and practical part: (Haque, Rahman, Itsuko, Mutahara, Tsutsumi, Islam, Mostofa, G \& Kayako, 2016 and Ray, Tumaini, \& Lorna, 2020):

The theoretical part was contained knowledge about teeth problems. It was implemented through lectures, posters, educational films, scenarios, and role-plays. The interview took approximately 35-45 minutes for each mother to answer and fill the questionnaire to assess the knowledge of mothers regarding teeth problems.

\section{The instructional guidelines included knowledge about oral health as follow:}

- Definition and number of temporary and permanent teeth.

- Oral importance care.

- Tooth decay causes.

- When the mother schedule the child's first trip to the dentist

- When the child start brushing their teeth

- How can prevent cavities and other teeth problems?

- Diet rich in calcium

- What dental problems happen

- Consequences of tooth decay.

- Oral care included use a toothbrush, use toothpaste that contains fluoride.

- Use a toothbrush 2 or 3 times /day.

- $\quad$ Exchange toothbrush every 3 months and visit dentists every 6 months.

The practical part was contained information about oral hygiene practices. The interview took approximately 35-45 minutes for each mother to answer and fill the questionnaire to assess the oral hygiene practices of mothers. It was implemented through lectures, demonstrations, posters, educational films.

The instructional guidelines included oral hygiene practices about oral health as follow:

Demonstration of oral hygiene practices as following 
- $\quad$ Putting the toothpaste on the brush

- $\quad$ Brushing teeth and gums with the brush

- Cleaning the outer teeth in a circular motion

- $\quad$ Cleaning the inner teeth

- $\quad$ Cleaning the digestive surfaces in a circle motion

- $\quad$ Cleaning the inner teeth from low to high

- $\quad$ All steps done

In the practical part all the studied mothers received a toothbrush and a toothpaste tube then oral hygiene steps was done individually and an observational checklist was collected by the researcher.

A tooth model was used to help studied mothers visualize the proper way of brushing with fluoridated toothpaste. Evaluation occurred after one month, each mother was re-interviewed to assess knowledge concerning their children's teeth and oral hygiene practices. Re-assessment of mother's knowledge was done and redemonstration of the proper oral hygiene practices technique was done using the same tool. This took 10 minutes and was individualized to ensure accuracy in completion of tools and to assess if steps of oral hygiene practices technique are correct or incorrect according to the observational checklist.

\section{Ethical considerations:}

Administrative permission was obtained through an issued letter from the Dean of Faculty of Nursing, Sohag University to the Directors of the antenatal clinic and each MCH center to achieve this study. The aim of the study was explained and the expected outcomes from the implementation of the study were included in this letter to obtain permission for data collection. The objective of the study was explained to the mothers.

The researcher informed the participants that, the study was voluntary; they were allowed to refuse to participate in the study. Mothers had the right to withdraw from the study at any time, without giving any reason. Mothers were assured that their information would be confidential and used for research purposes only.

\section{Statistical analysis:}


Data entry and statistical analysis were performed using SPSS for Windows, version 20. Frequencies and percentages for qualitative variables and mean and SDs for quantitative variables were represented descriptive statistics. Differences between the two means tests (t-test) were used. Chi-square (x2) test was used to compare qualitative parameters. Pearson's correlation coefficient $(г)$ test was used. Statistical significance was considered at $\mathrm{P}$-value $<0.05$.

\section{RESULTS}

Table (1): Reflected that $44 \%$ of the studied mothers were between $21<26$ years and their mean age $(19.9 \pm 6.67)$. Nearly one-third $(32 \%)$ of them had secondary education, $58 \%$ were housewives, majority of them $(85 \%)$ were rural residence.

Figure (1): Revealed that $70 \%$ of the studied mothers reported that the main source of information regarding teeth problems was doctors.

Table (2): Pointed out that there was an improvement in the studied mothers of preschool-age children's knowledge post implementing instructional guidelines as compared to pre-implementing significant guidelines. There was a highly statistically significant difference between pre/post one month of instructional guide preschoolagitation concerning the studied mothers of preschool-age children's knowledge regarding teeth problems after implementing instructional guidelines (P-value $<0.000)$.

Table (3): Revealed highly statistically significant differences were found between the studied mothers of preschool-age children's total knowledge pre and postinstructional guidelines implementation $(\mathrm{p}<0.001)$.

Concerning the steps of the oral hygiene practices, table (4) revealed that $23 \%$ and $88 \%$ respectively who done all the steps completely before and after the implementation of the instructional guidelines. Study mothers who done cleaning of the outer teeth in circle motion increased from $38 \%$ before the implementation of the instructional guidelines to $89 \%$ after the implementation of the instructional guidelines. While 44\% clean inner teeth before instructional guidelines implementation and $84 \%$ after it. More than half of mothers $(55 \%)$ reported they 
cleaned the digestive surfaces in a circular motion before the implementation of the instructional guidelines while $70 \%$ did this procedure after the implementation of the instructional guidelines. Nearly two-thirds $(61 \%)$ of the studied mothers cleaned the inner teeth from low to high before the instructional guidelines implementation and $80 \%$ after the implementation of the instructional guidelines.

Regarding oral hygiene practices, table (5) clarified a statistically significant difference was detected pre and post-instructional guidelines implementation $(\mathrm{p}<0.001)$.

Table (6): Revealed that there was a positive correlation $(\mathrm{P}=0.005)$ between knowledge scores and their practice post-one-month instructional guidelines implementation.

Table (1): Percentage distribution of the mothers of preschool-age children according to their characteristics $(n=260)$

\begin{tabular}{|l|c|c|}
\hline \multirow{2}{*}{ Item } & \multicolumn{2}{|c|}{ Studied mothers(260) } \\
\cline { 2 - 3 } & No. & \% \\
\hline women ' age in years & 57 & 22.0 \\
\hline $18<21$ & 114 & 44.0 \\
\hline $21<26$ & 68 & 26.0 \\
\hline $26<30$ & 21 & 8.0 \\
\hline $30<35$ & $19.9 \pm 6.67$ \\
\hline Mean \pm Stander deviation & 18 & 7.0 \\
\hline - women ' education & 52 & 20.0 \\
\hline - Illiterate & 52 & 20.0 \\
\hline -Read and write & 83 & 32.0 \\
\hline -Primary education & 55 & 21.0 \\
\hline -Secondary education & \multicolumn{2}{|l|}{} \\
\hline -University education & 109 & 42.0 \\
\hline Occupation & 151 & 58.0 \\
\hline - Employee & 221 & 85.0 \\
\hline - Housewife & 39 & 15.0 \\
\hline -Residence & \multicolumn{2}{|l}{} \\
\hline -Rural & \multicolumn{2}{|l}{} \\
\hline -Urban & \multicolumn{2}{|l|}{} \\
\hline
\end{tabular}




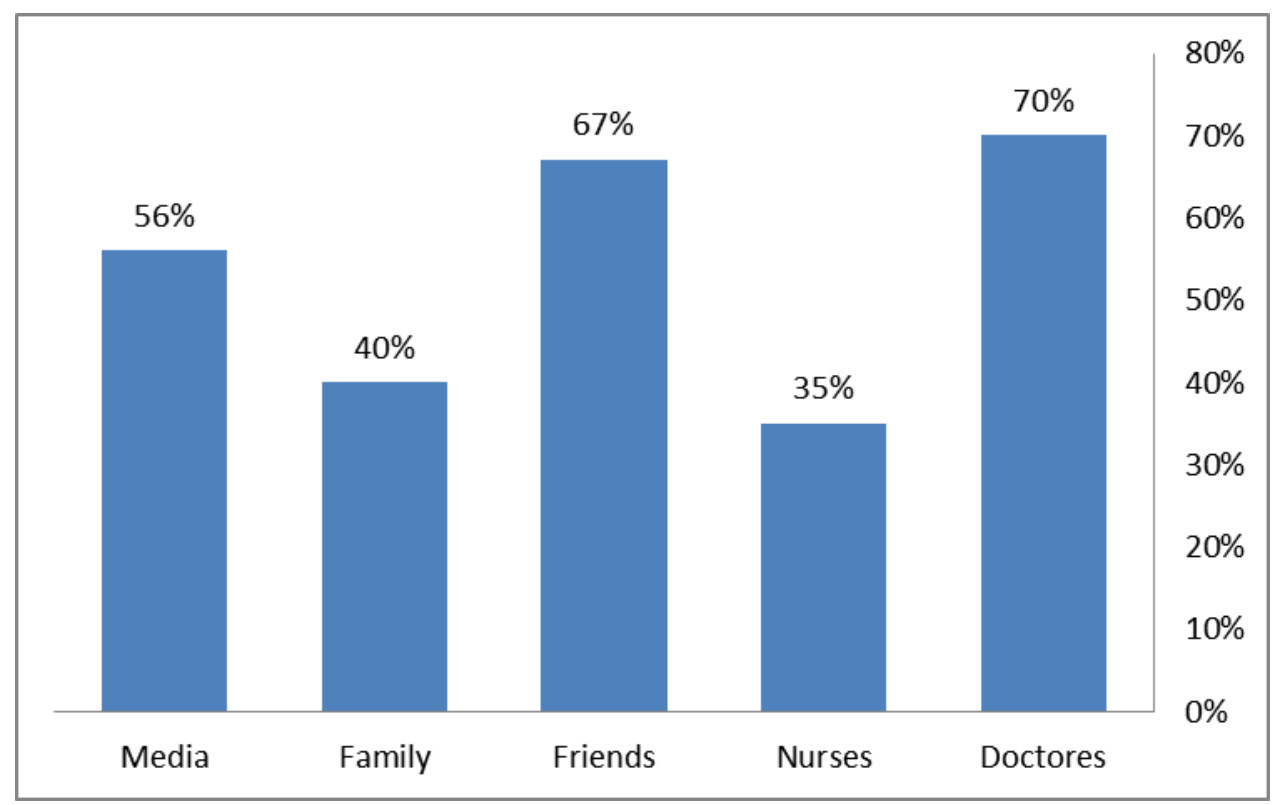

Figure (1): Percentage distribution of the studied mothers of preschool-age children regarding their source of knowledge about teeth problems

Table (2): Differences between pre and post-one-month implementation of instructional guidelines implementation among mothers of preschool-age children' knowledge regarding teeth problems

\begin{tabular}{|c|c|c|c|c|c|}
\hline \multirow{3}{*}{ Items } & \multicolumn{4}{|c|}{$n=260 \quad 100 \%$} & \multirow{3}{*}{ P-value } \\
\hline & \multicolumn{2}{|c|}{ Pre } & \multicolumn{2}{|c|}{ Post } & \\
\hline & No. & $\%$ & No. & $\%$ & \\
\hline \multicolumn{6}{|l|}{ Teeth importance } \\
\hline Don't know & 112 & 43 & 8 & 3 & \multirow[b]{2}{*}{0.000} \\
\hline Know & 148 & 57 & 252 & 97 & \\
\hline \multicolumn{6}{|l|}{ Types of teeth } \\
\hline - Don't know & 91 & 35 & 26 & 10 & \multirow{2}{*}{0.000} \\
\hline - Know & 169 & 65 & 234 & 90 & \\
\hline \multicolumn{6}{|l|}{ Teeth problem causes } \\
\hline - Don’t know & 117 & 45 & 57 & 22 & \multirow{2}{*}{0.000} \\
\hline - Know & 143 & 55 & 203 & 78 & \\
\hline \multicolumn{6}{|l|}{ Dietary habits cause teeth problem } \\
\hline - Don’t know & 94 & 36 & 31 & 12 & \multirow[b]{2}{*}{0.000} \\
\hline- Know & 166 & 64 & 229 & 88 & \\
\hline \multicolumn{6}{|l|}{ Oral care } \\
\hline - Don't know & 109 & 42 & 26 & 10 & \multirow{2}{*}{0.000} \\
\hline - $\quad$ Know & 151 & 58 & 234 & 90 & \\
\hline
\end{tabular}

*Statistically significant level at $\mathrm{P}<.05$ 
Table (3): Total knowledge of the studied mothers of preschool-age children pre and post-instructional guidelines implementation

\begin{tabular}{|c|c|c|c|c|c|c|}
\hline \multirow{3}{*}{$\begin{array}{c}\text { Total } \\
\text { knowledge }\end{array}$} & \multicolumn{4}{|c|}{ No $=(260)$} & \multirow{3}{*}{$\mathbf{T}$} & \multirow{3}{*}{ p-value } \\
\hline & \multicolumn{2}{|c|}{ Pre } & \multicolumn{2}{|c|}{ Post } & & \\
\hline & No & $\%$ & No & $\%$ & & \\
\hline Poor (1-4) & 36 & 14 & 8 & 3 & \multirow{3}{*}{4.074} & \multirow{3}{*}{$<0.001 *$} \\
\hline Average (5-8) & 208 & 80 & 70 & 27 & & \\
\hline Good (9-12) & 16 & 6 & 182 & 70 & & \\
\hline
\end{tabular}

*Statistically significant level at $\mathrm{P}<.05$

Table (4): Differences of pre and post-one-month instructional guidelines implementation mothers of preschool-age children's practices regarding teeth problems

\begin{tabular}{||l|c|c|c|c|c|c|c|c||}
\hline \multirow{2}{*}{\multicolumn{1}{c|}{ Steps }} & \multicolumn{3}{c|}{ Pre } & \multicolumn{4}{c||}{ Post } \\
\cline { 2 - 10 } & \multicolumn{2}{|c|}{ Yes } & \multicolumn{2}{c||}{ No } & \multicolumn{2}{c||}{ Yes } & \multicolumn{2}{c||}{ No } \\
\cline { 2 - 10 } & No & $\%$ & No & $\%$ & No & $\%$ & No & $\%$ \\
\hline 1- Putting the toothpaste on the brush & 252 & 97 & 8 & 3 & 257 & 99 & 1 & 1 \\
\hline 2- Brushing teeth and gums with the brush & 234 & 90 & 26 & 10 & 244 & 94 & 16 & 6 \\
\hline 3- Cleaning the outer teeth in a circular motion & 99 & 38 & 161 & 62 & 231 & 89 & 29 & 11 \\
\hline 4- Cleaning the inner teeth. & 114 & 44 & 146 & 56 & 218 & 84 & 42 & 16 \\
\hline 5- Cleaning the digestive surfaces in a circle motion & 143 & 55 & 117 & 45 & 182 & 70 & 78 & 30 \\
\hline 6- Cleaning the inner teeth from low to high & 159 & 61 & 101 & 39 & 208 & 80 & 52 & 20 \\
\hline 7- All steps done & 60 & 23 & 200 & 77 & 229 & 88 & 31 & 12 \\
\hline \hline
\end{tabular}

Table (5): Total oral hygiene practices as done by the studied mothers of preschoolage children pre and post teeth problems instructional guidelines implementation $(n=260)$

\begin{tabular}{|l|c|c|c|c|c|c|}
\hline \multirow{2}{*}{\begin{tabular}{c}
\multirow{2}{*}{$\begin{array}{c}\text { Total } \\
\text { knowledge }\end{array}$} \\
\cline { 2 - 5 }
\end{tabular}} & \multicolumn{4}{|c|}{ Pre } & \multirow{2}{*}{ T } & \multirow{2}{*}{ p-value } \\
\cline { 2 - 5 } & No & $\mathbf{\%}$ & No & $\mathbf{\%}$ & & \\
\hline Done & 88 & 34 & 34 & 13 & \multirow{2}{*}{3.585} & \multirow{2}{*}{$<0.001^{*}$} \\
\hline Not done & 172 & 66 & 226 & 87 & & \\
\hline
\end{tabular}

*Statistically significant level at $\mathrm{P}<.05$ 
Table (6): Correlation coefficient between total studied mothers' knowledge and practice scores during pre and post-one-month teeth problems instructional guidelines implementation

\begin{tabular}{|c|c|c|c|c|}
\hline \multirow{4}{*}{ Items } & \multicolumn{4}{|c|}{ Practice } \\
\hline & \multicolumn{2}{|r|}{$\mathrm{No}=260$} & \multicolumn{2}{|c|}{$100 \%$} \\
\hline & \multicolumn{2}{|r|}{ Pre } & \multicolumn{2}{|c|}{ After one month } \\
\hline & $\mathbf{R}$ & $\mathbf{P}$ & $\mathbf{R}$ & $\mathbf{P}$ \\
\hline - Total knowledge pre-test & 0.037 & 0.813 (N.S) & --- & --- \\
\hline - Total knowledge post-test & --- & --- & 0.412 & 0.005 \\
\hline
\end{tabular}

\section{DISCUSSION:}

Poor oral health can harm the child's ability to eat, sleep and socialize and also, can affect the ability to teach (Bach \& Manton, 2014). ). It is important to maintain oral health in early childhood because the presence of caries in the primary dentition is meaning the strongest predictor of this disease in permanent teeth (Anil \& Anand, 2017). There is an improvement in their knowledge and practices compared to before instructional guidelines implementation. Therefore, it ensures the importance of instructional guidelines implementation about teeth problems for improving the mothers' knowledge and practices which reflects on children with healthy behaviors.

The finding of the present study indicated that more than two-thirds of the mothers reported that the main source of information regarding oral health was doctors. This is indicated the desire of mothers to know healthy and correct information from confident sources.

The results of the present study revealed that a highly statistically significant difference was observed between pre/post one month of instructional guidelines implementation about the studied mothers of preschool-age children's knowledge regarding teeth problem (P-value <0.000). This result reflects the benefit of instructional guideline implementations, which met the mothers' needs and provide them with sufficient knowledge to prevent and overcome their children's teeth problems. The finding is supported by Ray, Tumaini, \& Lorna, (2020) who studied in Kisarawe, Tanzania metrics the prevalence of dental caries among preschool children 
aged 4-6 years in deciduous teeth and oral health-related quality of life and found that there was unsatisfactory knowledge prevalence regarding oral hygiene pre-program and related his finding to decreasing of supervision from mothers or caregivers during children' tooth brushing and knowledge deficit among mothers concerning adequate oral hygiene practices.

The same results were found by El-Nasr, (2017) who conducted a study at ElQalyubia Governorate about intervention programs for primary school children about oral health and reported that a significant difference was detected between the study participants' total knowledge pre and that post-program intervention. Similarly, Haque, Rahman, Itsuko, Mutahara, Tsutsumi, Islam, Mostofa, \& Kayako, (2016) in Bangladesh conducted a study about the effect of school-based education about oral health on preventing untreated dental caries and improving knowledge, attitude, and practices among children and found a significant difference in most indicators regarding knowledge variable pre and post the program.

The current result illustrated that statistical differences were noticed between the studied mothers of preschool-age children's total knowledge pre and postinstructional guidelines implementation $(\mathrm{p}<0.001)$. This result reflects the need of the studied mothers of children in preschool age to increase their awareness and know adequate practicing to improve their information about oral health for their children and this clarifies the importance of instructional guidelines implementation. These results are very logical because they were giving the guidelines and there is an increase in their knowledge, which reflects the need of those participants for effective guidelines about oral health. This study is Following Farag, Rashed, \& Fouad, (2014) who studied the oral health status of preschool children in the El-Suez governorate concerning dental care given and the influence of oral health intervention program and found that the oral health education program was an effective method for improving the oral knowledge, habits, and attitude. Also, these results are in agreement with Shenoy and Sequeira (2013) who conducted a study in Indian about the effect of dental education programs in a school on improving and promoting oral health knowledge and oral hygiene practices and status among school children aged from 12- to 13-year-old.

Similary, Abu-Elenen, Abdella, \& Elkazaz, (2015), who showed in their study about the impact of the oral care educational program among school-age children on 
their knowledge, practice, and their self-efficacy that the application of oral health programs was effective in improving and increasing dental health knowledge and practice and indicated that there were statistically significant improvements in the participant's oral health knowledge before and that after intervention program about the teeth importance, tooth decay causes, and consequences of tooth decay.

The current results revealed that the majority of participants were done all the steps completely before and after the implementation of the instructional guidelines. This result may be explained by mothers having good knowledge about oral care after instructional guidelines implementation. This result was supported by researchers Farag, Rashed, \& Fouad, (2014) who reported that before the oral health intervention program more than a quarter of participants performed all steps of brushing teeth but after the program, the percentage improved to more than half. Also, match with the results of the study of Abu-Elenen, Abdella, \& Elkazaz, (2015) to examine the effect of the oral care educational program among school-aged children on their knowledge, practice, and self-efficacy agrees with the results of the current research. Similarly, the study conducted by Haque, Rahman, Itsuko, Mutahara, Tsutsumi, Islam, Mostofa, \& Kayako, (2016) revealed a significant improvement in oral health practices among the studied participants occurred after giving adequate information.

The results are In agreement with the study carried out at El-Ismailia Governorate among preschool children about " oral health status among children in EL-Ismailia at preschool stage concerning dental care given and the influence of oral health intervention program" and revealed a significant increase in the children's normal diet and tooth brushing, and a decrease in the prevalence of children who consumed sugar after health education program (Yehia, Rashed, Elshahawy, \& Elhadidi, 2013).

The results of the present study illustrated that there was an increasing and improvement in the percentage regarding all the steps of the oral hygiene practices, before and after the implementation of the instructional guidelines. This is reflected the importance of instructional guidelines implementation for mothers of preschool children with teeth problems. This finding came in agreement with the results of a study done by Shenoy, Krishnan, \& Sequeira, (2017) in India who found that school 
dental education program was successful in improving and increasing oral health knowledge, practices, oral hygiene status, and gingival health of the children at school age. Besides, a similar finding came in the same line with the result of a study conducted by Macpherson, Anopa, \& McMahon, (2017) in Scotland who found improvement in oral habits and attitudes after applying for the program.

The present study reveals that statistically significant differences were noticed pre and post-instructional guidelines implementation $(\mathrm{p}<0.001)$. This may be due to applying oral hygiene practice through many attractive methods. The same results were detected by Haque Rahman, Itsuko, Mutahara, Tsutsumi, Islam, Mostofa, \& Kayako, (2016) who found significant differences in almost all the indicators of knowledge variables pre and post-the-implementation of the instructional guidelines.

The present study revealed that there was a positive correlation $(\mathrm{P}=0.005)$ between knowledge scores and their practice post-one-month instructional guidelines implementation. This indicated the importance of improving the mothers' knowledge and self-care practices to help their children still growing and learning would be very easy for them and help to acquire good knowledge and apply it. These results were settled with Caroline, Sthefanie, Marília, \& Maria, (2018) who studied "Effectiveness of a Preventive Oral Health Program in Preschool Children" and stated that the preventive program in oral health has positive results in the reduction of the dental problem which would be related to the improvement in oral hygiene habits

\section{CONCLUSIONS:}

Based on the findings and hypotheses of the current study, the study findings concluded the results support the research hypothesis in which implementing instructional guidelines regarding teeth problems had a significant positive effect on improving new mothers of preschool children's knowledge and practices. There was a statistically significant $(\mathrm{P}=0.005)$ correlation between total knowledge scores and their practice post one month of instructional guidelines implementation regarding teeth problems. 


\section{RECOMMENDATIONS:}

In light of the current study results, the following recommendations are proposed:

Mothers should be provided with instructional guidelines implementation regarding teeth problems and oral health and counseling are given to them about preventive guidelines to be conducted regularly at maternal and child health centers. Mothers should be given practical education to help their children to know and apply oral hygiene habits as mothers are responsible to improve the importance of teeth problems and their care among preschool children. Further researches are required on a larger sample of mothers to be generalized and about their role in early detection of teeth problem, healthy dietary habits to prevent teeth decay.

\section{REFERENCES:}

Abu-Elenen, N., Abdella N., \& Elkazaz R. (2015): Effect of an oral care educational program on the knowledge, practice, and self-efficacy among school-age children. Int J Res Stud Biosci 3:53-61.

Anil, S., \& Anand, P. (2017): Early childhood caries: prevalence, risk factors, and prevention. Front Pediatr; 5:157.

Arora, R., \& Sharma, A. (2012): Evaluation of Awareness among Muslim Parents of Preschool Children in Udaipur City of Rajasthan India, Regarding the Importance of Primary Dentition. Journal of Oral Health Community Dentistry; 6(2): 64-68.

Bach, K., \& Manton, D. (2014): Early childhood caries: a New Zealand perspective, J Prim Health Care, 6(2), 169-74.

Bhayya, D., \& Shyagali, T. (2013): "Traumatic injuries in the primary teeth of 4- to 6-year-old school children in Gulbarga city, India, A prevalence study. Oral Health and Dental Management 12.1 17-23. 
Caroline, Z., Sthefanie, P., Marília, J.B., \& Maria, S. (2018): Effectiveness of a Preventive Oral Health Program in Preschool Children, available at: http://dx.doi.org/10.20396/bjos.v17i0.8652647.

Clausson, E. K. (2008): School Health Nursing, Perceiving, Recording and Improving School Children's Health, Doctoral Thesis at the Nordic School of Public Health, Sweden.

El-Nasr, A. (2017): Oral health intervention program among primary school children at El-Qalyubia Governorate, Egyptian nursing journal, Volume: 14 | Issue: 2 | Page: 100-108.

Farag, S., Rashed, A., \& Fouad, W. (2013): Oral Health Status of Preschool Children in El-Suez Governorate about Dental Care Given and the Influence of Oral Health Intervention Program. Cairo: Faculty of Oral and Dental Medicine, Cairo University.

Gimenez, T., Bispo, B.A., Souza, D.P., Viganó, M.E., Wanderley, M.T., \& Mendes, F.M. (2016): Does the decline in caries prevalence of Latin American and Caribbean children continue in the new century? Evidence from a systematic review with meta-analysis, PLoS One; 11(10):e0164903. https://doi.org/10.1371/journal.pone.0164903Links ]

Grossman, W., Cohen, J., \& Isman, B. (2010): Integrating Oral Health into School Health Programs and Policies. www.dentalhealthfoundation.org.

Haque, S., Rahman, M., Itsuko, K., Mutahara, M., Tsutsumi, A., Islam, J., Mostofa, G., \& Kayako, S. (2016): Effect of school-based oral health education in preventing untreated dental caries and increasing knowledge, attitude, and practices among adolescents in Bangladesh. Bio-Med Central Oral Health 16:44.

Lemos, L.V., Zuanon, A.C., Myaki, S.I., \& Walter, L. (2018): Experiência de care denarii me carinas atendidas me um program de Odontology para babes, Einstein (São Paulo); 9(4):503-507. [PubMed][Google Scholar] 
Macpherson, L. M., Anopa, Y., \& McMahon, A. D. (2017): National Supervised Toothbrushing Program and Dental Decay in Scotland. J DENT RE; 92: 109-113.

Petersen, P. E. (2014): World Health Organization global policy for improvement of oral health -World Health Assembly, Int Dent J; 58:115-21. DOI: 10.1111/j.1875-595X.tb00185.x. [PubMed] [CrossRef] [Google Scholar]

Ray, M., Tumaini, S., \& Lorna, C. (2020): Metrics Prevalence of dental caries in deciduous teeth and oral health-related quality of life among preschool children aged 4-6 years in Kisarawe, Tanzania, BMC Oral Health volume 20.

Saldunaite, K., Bendoraitiene, E.A., \& Slabšinskiene, E. (2014): The role of parental education and socioeconomic status in dental caries prevention among Lithuanian children. Medicine (Kaunas); 50 (3):156-161. 10.1016/j.medici.07.003.

Shenoy, R., Krishnan, V., \& Sequeira, S. (2017): Effectiveness of a school dental education program in improving oral health knowledge and oral hygiene practices and status of school children. Indian J Dent Res; 21:253-9.

Shenoy, R., \& Sequeira, P. (2013): Effectiveness of a school dental education program in improving oral health knowledge and oral hygiene practices and status of 12- to 13- year-old school children. Indian J Dent Res [cited Oct 25]; 21:253-9.

Suma, H., Hugar, S., Nalawade, T., Sinha, A., Hugar, S., \& Mallikarjuna, R. (2016): Knowledge, attitude, and practices of oral health care in the prevention of early childhood caries among parents of children in Belagavi city: a Questionnaire Study. J Family Med Prim Care; 5(2):286-90.

World Health Organization (2018): Stop TB Partnership Advocacy, communication and social mobilization for TB control: a guide to developing knowledge, attitude and practice surveys. Geneva: World Health Organization; 35p.

Yehia, S., Rashed, M., Elshahawy, O., \& Elhadidi, S. (2013): Oral Health Status of Preschool Children in EL-Ismailia Concerning Dental Care Given and the 
Influence of Oral Health Intervention Program [Master thesis in Pedodontics and Dental Public Health]. Cairo: Faculty of Oral \& Dental Medicine, Cairo University.

\section{تأثير الإرشادات التعليمية على ممارسات الأمهات الجدد فيما يتعلق بمشاكل أسنان الأطفال

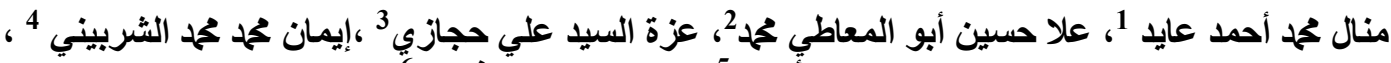

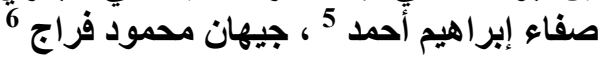

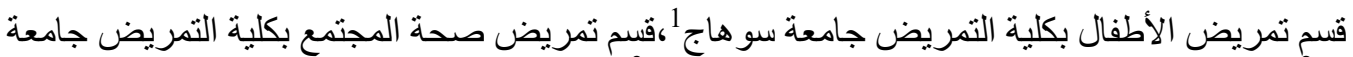

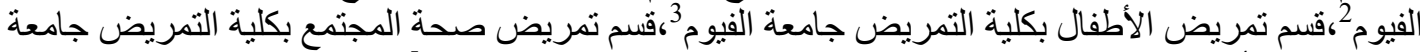

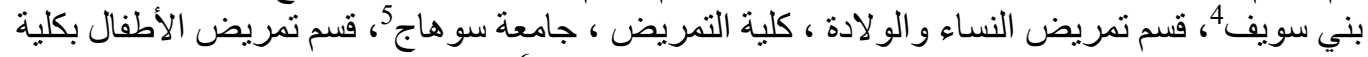

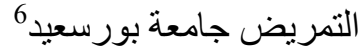

\section{الخلاصة}

إن فهم الأمهات للمعلومات و الممارسات المتعلقة بمشاكل أسنان أطفالهن يمكن أن يدعمهن ويساعدهن في رعاية أطفالهن. الهدف: تقييم تأثير الإرشادات التعليمية على ممارسات الأمهات الجدد فيما بتعلق بمشاكل أسنان الأطفال.التصميم:تم استخدام تصميم بحث شبه تجريبي مع الاختبار القبلي و البعدي. اماكن جمع العينة: نم إجراء البحث وجمع العينات من العيادة الخارجية للحو امل بمستشفى جامعة سوهاج ، و مركزان لصحة الأم و الطفل

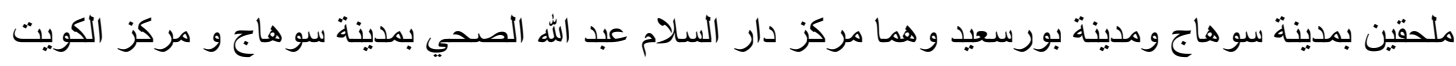

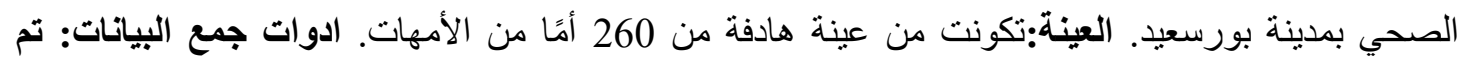

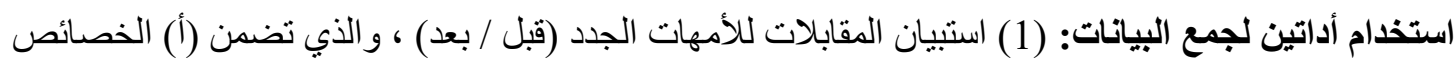
الديموغر افية ؛ و (ب) معرفة الأمهات الجدد (2) قائمة لملاحظة ممارسة نظافة الفم (قبل / بعد). النتائج:اوضحت النتائج أن أعمار الأمهات تتراوح بين 18 إلى 35 سنة ، ومتوسط العمر 23.2 ـ 4.5 سنة. كانت هناك تحسينات ملحوظة في معلومات وممارسات الأمهات فيما يتعلق بمشاكل أسنان الأطفال بعد تنفيذ الإرشادات التعليمية (P= P P.005). الخلاصة: نطبيق الإرشادات التعليمية المنعلقة بمشاكل أسنان ألاطفال كان لها تأثير إيجابي على تحسين معلومات وممارسات للأمهات الجدد. التوصيات:يجب إجر اء الإرشادات التهات التعليمية

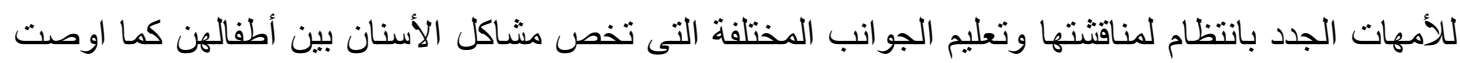
بتكرار الدر اسة الحالية مع عينة أكبر مع المتابعة. الكلمات المرشدة: إرشادات إرشادية ، الأمهات الجدد لأطفال ما قبل المدرسة ، مشاكل الأسنان 